\title{
Fast-Dissolving, Prolonged Release, and Antibacterial Cyclodextrin/ Limonene-Inclusion Complex Nanofibrous Webs via Polymer-Free Electrospinning
}

Zeynep Aytac, ${ }^{\dagger,}$ Zehra Irem Yildiz, ${ }^{\dagger+}$ Fatma Kayaci-Senirmak, ${ }^{\dagger,}$ Nalan Oya San Keskin, Semran Ipek Kusku, ${ }^{\ddagger} \perp$ Engin Durgun, ${ }^{\dagger, \ddagger}$ Turgay Tekinay, $\|, \#$ and Tamer Uyar, ${ }^{*},+\neq$

${ }^{\dagger}$ Institute of Materials Science \& Nanotechnology, Bilkent University, Ankara 06800, Turkey

${ }^{\ddagger}$ UNAM-National Nanotechnology Research Center, Bilkent University, Ankara 06800, Turkey

${ }^{\S}$ Department of Biology, Polatlı Faculty of Literature and Science, Gazi University, Ankara 06900, Turkey

"Life Sciences Application and Research Center, Gazi University, Ankara 06830, Turkey

${ }^{\perp}$ Department of Engineering Physics, Istanbul Medeniyet University, Istanbul 34700, Turkey

\# Department of Medical Biology and Genetics, Faculty of Medicine, Gazi University, Ankara 06560, Turkey

Supporting Information

ABSTRACT: We have proposed a new strategy for preparing free-standing nanofibrous webs from an inclusion complex (IC) of a well-known flavor/fragrance compound (limonene) with three modified cyclodextrins ( $\mathrm{HP} \beta \mathrm{CD}, \mathrm{M} \beta \mathrm{CD}$, and $\mathrm{HP} \gamma \mathrm{CD}$ ) via electrospinning $(\mathrm{CD} /$ limonene-IC-NFs) without using a polymeric matrix. The experimental and computational modeling studies proved that the stoichiometry of the complexes was $1: 1$ for $\mathrm{CD} /$ limonene systems. $\mathrm{M} \beta \mathrm{CD} /$ limonene-IC-NF released much more limonene at 37,50 , and $75{ }^{\circ} \mathrm{C}$ than $\mathrm{HP} \beta \mathrm{CD}$ /limonene-IC-NF and $\mathrm{HP} \gamma \mathrm{CD} /$ limonene-IC-NF because of the greater amount of preserved limonene. Moreover, $\mathrm{M} \beta \mathrm{CD} /$ limonene-IC-NF has released only $25 \%(\mathrm{w} / \mathrm{w})$ of its limonene, whereas $\mathrm{HP} \beta \mathrm{CD} /$ /imonene-IC-NF and $\mathrm{HP} \gamma \mathrm{CD} /$ limonene-IC-NF released 51 and $88 \%(\mathrm{w} / \mathrm{w})$ of their limonene in 100 days, respectively. $\mathrm{CD} /$ limonene-IC-NFs exhibited high antibacterial activity against $E$. coli and $S$. aureus. The water solubility of limonene increased significantly and $\mathrm{CD} /$ limonene-IC-NFs were dissolved in water in a few seconds. In brief, $\mathrm{CD} /$ limonene-IC-NFs with fastdissolving character enhanced the thermal stability and prolonged the shelf life along with antibacterial properties could be quite applicable in food and oral care applications.

KEYWORDS: electrospinning, essential oil, modified cyclodextrins, computational modeling, antibacterial activity

\section{INTRODUCTION}

Cyclodextrins (CDs) (Figure 1a) are ideal candidates for making host-guest inclusion complexes (IC) with a variety of active compounds thanks to their inherent cavity geometry and characteristic features. The internal cavity of a CD is composed of glucose residues that exhibit a hydrophobic nature, whereas the external part of a CD has hydrophilic character due to the hydroxyl groups. The great significance of CDs lies in the access of nonpolar guest molecules to their cavity and further forming host-guest ICs by replacing the water molecules. ${ }^{1,2}$ This inclusion has been proven to be an efficient approach to improving the molecular stability and bioavailability of numerous drugs, essential oils, and flavors and fragrances. ${ }^{1}$ The incorporated guest molecules offer a number of advantages, including an enhancement of the solubility and thermal stability. Beside native $\mathrm{CDs}(\alpha-\mathrm{CD}, \beta-\mathrm{CD}, \gamma-\mathrm{CD})$, significant effort has been devoted to the synthesis of chemically modified $\mathrm{CDs}(\mathrm{HP} \beta \mathrm{CD}, \mathrm{M} \beta \mathrm{CD}, \mathrm{HP} \gamma \mathrm{CD})$ to improve the solubility and complexing property of CDs for superior performance in a variety of applications including drug delivery and food. ${ }^{1,2}$

The electrospinning approach has been universally acknowledged to produce functional fibers with nanoscale diameter from a variety of materials including polymers, inorganic materials, and composites. ${ }^{3}$ The exceptional characteristics of electrospun nanofibers have led to broad applications ranging from food packaging, wound dressing, and biomedical to filtration. In addition, nanofibers are effectively functionalized with number of molecules, which further extends their application areas. ${ }^{3}$ In general, polymers have been taken as a material/matrix for the fabrication of nanofibers owing to the chain entanglement and overlapping between the polymer chains. ${ }^{4}$ However, Celebioglu and Uyar successfully demonstrated the electrospinning of polymer-free nanofibers from various native and modified CDs without using any polymeric carrier matrix. $^{5-9}$ The self-assembly and aggregation characteristics of $\mathrm{CD}$ molecules in concentrated solutions via the formation of intermolecular hydrogen bonding enable the production of nanofibers in the absence of a polymer matrix. Furthermore, our research group has successfully produced CD-IC-incorporated polymeric nanofibers. ${ }^{10-20}$ However, loading fewer guest molecules (only up to $\sim 5 \%, \mathrm{w} / \mathrm{w}$ ) in nanofibers and sometimes the necessity of using organic

Received: June 11, 2016

Revised: September 5, 2016

Accepted: September 11, 2016

Published: September 12, 2016 

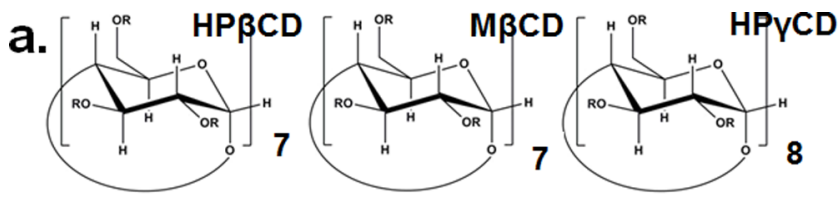

$\mathrm{R}=\mathrm{CH}_{2} \mathrm{CH}(\mathrm{OH}) \mathrm{CH}_{3}$ or $\mathrm{H}$

$\mathrm{R}=\mathrm{CH}_{3}$ or $\mathrm{H}$

$\mathrm{R}=\mathrm{CH}_{2} \mathrm{CH}(\mathrm{OH}) \mathrm{CH}_{3}$ or $\mathrm{H}$<smiles>C=C(C)[C@H]1CC=C(C)CC1</smiles>
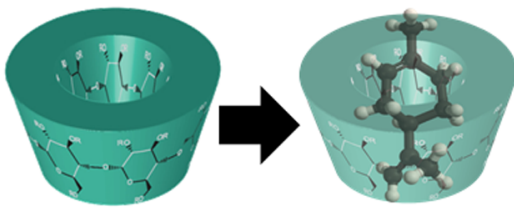

limonene

cyclodextrin (CD)

CD/limonene-IC

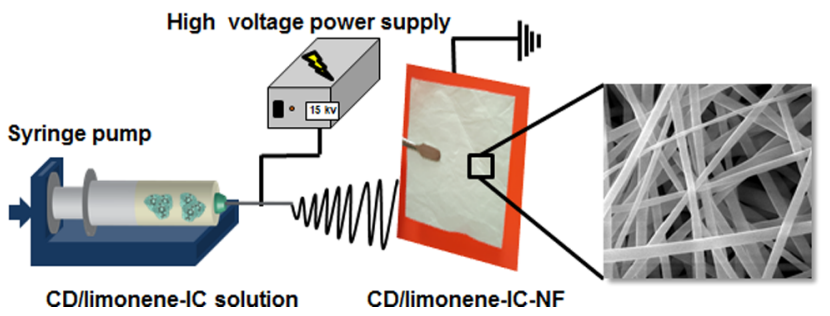

Figure 1. Chemical structures of (a) $\mathrm{HP} \beta \mathrm{CD}, \mathrm{M} \beta \mathrm{CD}$, and $\mathrm{HP} \gamma \mathrm{CD}$, (b) chemical structure of limonene, with a schematic representation of $\mathrm{CD}$ and $\mathrm{CD} /$ limonene-IC, and (c) a schematic representation of the electrospinning of nanofibers from $\mathrm{CD} /$ limonene-IC solution.

solvents were unavoidable. Therefore, the electrospinning of polymer-free CD-IC nanofibers was achieved successfully with a much higher loading capacity of guest molecules (up to $\sim 10-$ $15 \%, \mathrm{w} / \mathrm{w}$ ) in aqueous solution. ${ }^{21,22}$ These polymer-free CD-IC nanofibers may open up new possibilities for various applications including cosmetic, biomedical, food packaging, and flavor/fragrance releasing.

Essential oils (EOs) are volatile complex compounds that are synthesized in plants and have a strong odor. It has been well reported that EOs possess antimicrobial, antioxidant, antifungal, antiviral, anticancer, insecticidal, and anti-inflammatory properties. $^{29}$ Therefore, interest has been raised in using EOs in the pharmaceutical, cosmetic, and food industries. The impressive reports in the literature on EOs are mainly focused on the encapsulation of EOs to increase their solubility and decrease their volatility. ${ }^{23}$ Limonene (Figure $1 \mathrm{~b}$ ), monocyclic monoterpene, is the major component of citrus oils found in orange, lemon, mandarin, and grapefruit. It is a highly volatile compound extracted from plants and widely used in perfumes, creams, and soaps; as a flavor additive for food applications; and as fragrances in household cleaning products. ${ }^{24}$ Different approaches including complex formation with $\mathrm{CDs}^{25-29}$ and encapsulation in electrospun nanofibers ${ }^{30,31}$ were proposed in order to protect limonene from volatilization and control its release rate. Further, Fuenmayor et al. demonstrated the encapsulation of limonene $/ \beta$-CD-IC containing only $3.1 \mathrm{wt} \%$ of a pullulan membrane. ${ }^{32}$

In this study, an IC of three modified CDs ( $\mathrm{HP} \beta \mathrm{CD}, \mathrm{M} \beta \mathrm{CD}$, and $\mathrm{HP} \gamma \mathrm{CD}$ ) and limonene was prepared in a 1:1 molar ratio (Figure $1 \mathrm{~b}$ ), and then electrospinning was performed without using any polymer matrix to obtain $\mathrm{CD} /$ limonene-IC-NF (Figure 1c). A phase solubility test was used to decide the solubility change in the limonene by the addition of different $\mathrm{CDs}$ at various concentrations. The morphology of $\mathrm{CD} /$
limonene-IC-NFs was evaluated using SEM imaging. The chemical, structural, and thermal characterization of $\mathrm{CD} /$ limonene-IC-NFs was examined by using ${ }^{1} \mathrm{H}$ NMR, TGA, $\mathrm{XRD}$, and DSC. Computational modeling studies were carried out to investigate the stoichiometry and the most favorable orientation of the guest to form a complex with each $\mathrm{CD}$. The short-term temperature-dependent release $\left(37,50\right.$, and $\left.75{ }^{\circ} \mathrm{C}\right)$ of limonene from $\mathrm{CD} /$ limonene-IC-NFs was measured using HS GC-MS for $3 \mathrm{~h}$, whereas the long-term release of limonene from nanofibers at room temperature (RT) was measured by TGA for 100 days. The antibacterial activity of nanofibers was tested against Escherichia coli (E. coli) and Staphylococcus aureus ( $S$. aureus) using a colony-counting method.

\section{EXPERIMENTAL PROCEDURES}

Materials. Limonene (97\%, Sigma, Germany) and deuterated dimethyl sulfoxide (DMSO- $d_{6}$, minimum degree of deuteration $99.8 \%$ for NMR spectroscopy, Merck, Germany) were purchased and used as received without any further purification. Hydroxypropyl- $\beta$-cyclodextrin $(\mathrm{HP} \beta \mathrm{CD})$, methylated- $\beta$-cyclodextrin $(\mathrm{M} \beta \mathrm{CD})$, and hydroxypropyl- $\gamma$-cyclodextrin $(\mathrm{HP} \gamma \mathrm{CD})$ were kindly donated by Wacker Chemie (Germany). The water used in the experiments was distilleddeionized from a Millipore Milli-Q ultrapure water system.

Preparation of Electrospinning Solutions. CD/limonene-ICs was formed in aqueous solution $(0.5 \mathrm{~mL})$ by using three types of modified CDs ( $\mathrm{HP} \beta \mathrm{CD}, \mathrm{M} \beta \mathrm{CD}$, and $\mathrm{HP} \gamma \mathrm{CD})(1 \mathrm{~g})$ in a $1: 1 \mathrm{molar}$ ratio with limonene $(0.093,0.119$, and $0.084 \mathrm{~g})$. First, CDs $(200 \%$, w/ $\mathrm{v}$ ) were placed in water and the solutions were stirred at room temperature (RT) until dissolving. Then, limonene was added to the solutions, and the resulting solutions were stirred at RT overnight. Finally, CD/limonene-IC solutions that are turbid were obtained, and then, clear and homogeneous solutions were obtained with the dissolution of limonene after $12 \mathrm{~h}$. Electrospinning was performed after $12 \mathrm{~h}$ of stirring, and $\mathrm{HP} \beta \mathrm{CD} /$ limonene-IC-NF, $\mathrm{M} \beta \mathrm{CD} /$ limonene-IC-NF, and $\mathrm{HP} \gamma \mathrm{CD} /$ limonene-IC-NF webs were produced. The viscosity, conductivity of $\mathrm{CD} /$ limonene-IC solutions, and average fiber diameter (AFD) values of $\mathrm{CD} /$ limonene-IC nanofibers (CD/ limonene-IC-NF) are shown in Table 2. Pure CD nanofibers without limonene (HP $\beta$ CD-NF, $M \beta C D-N F$, and $\mathrm{HP} \gamma \mathrm{CD}-\mathrm{NF}$ ) were produced for comparative measurements according to our previous reports. ${ }^{5,6}$

Electrospinning of Nanofibers. CD/limonene-IC solutions were separately loaded into a $1 \mathrm{~mL}$ plastic syringe (metallic needle having a $0.4 \mathrm{~mm}$ inner diameter). The solutions were pumped through a syringe pump (KD Scientific, KDS-101, USA) at $0.5 \mathrm{~mL} / \mathrm{h}$ rate. Grounded metal covered with aluminum foil was used as a collector and placed $10 \mathrm{~cm}$ from the needle tip. The electric field $(15-20 \mathrm{kV})$ was applied from a high-voltage power supply (AU Series, Matsusada Precision Inc., Japan). Electrospinning experiments were carried out in an enclosed Plexiglas box at $25{ }^{\circ} \mathrm{C}$ and $18 \%$ relative humidity. The nanofibers were kept in the refrigerator until their use in analysis.

Measurements and Characterization. Phase-solubility measurements were performed in water according to the method of Higuchi and Connors. ${ }^{33}$ An excess amount of limonene was added to $5 \mathrm{~mL}$ of aqueous solutions containing increasing amounts of $\mathrm{HP} \beta \mathrm{CD}, \mathrm{M} \beta \mathrm{CD}$, and $\mathrm{HP} \gamma \mathrm{CD}$. The suspensions were shaken at RT for $24 \mathrm{~h}$. After equilibrium was achieved, the suspensions were filtered through a 0.45 $\mu \mathrm{m}$ membrane filter and diluted with water. To determine the amount of limonene dissolved, UV spectroscopy measurements were made at $235 \mathrm{~nm}$ (Varian, Cary 100). The phase solubility diagrams were drawn by plotting the molar concentration of limonene found in the solution against the molar concentration of CDs. The experiments were carried out in triplicate, and each data point is the average of three determinations.

The viscosity measurements of $\mathrm{HP} \beta \mathrm{CD} /$ limonene-IC, $\mathrm{M} \beta \mathrm{CD} /$ limonene-IC, and $\mathrm{HP} \gamma \mathrm{CD} /$ limonene-IC solutions were performed at RT via an Anton Paar Physica MCR 301 rheometer equipped with a cone/plate accessory (spindle type CP 40-2) at a constant shear rate of 
$100 \mathrm{~s}^{-1}$. The solution conductivity for $\mathrm{CD} /$ limonene-IC solutions was measured with an Inolab $\mathrm{pH} / \mathrm{Cond}$ 720-WTW.

The morphology of $\mathrm{HP} \beta \mathrm{CD} /$ limonene-IC-NF, $\mathrm{M} \beta \mathrm{CD} /$ limoneneIC-NF, and $\mathrm{HP} \gamma \mathrm{CD} /$ limonene-IC-NF was investigated using scanning electron microscopy (SEM, FEI-Quanta 200 FEG). Prior to taking SEM images, nanofiber samples were placed on metal stubs by using double-sided copper tape, and in order to minimize the charging problem during SEM examination, samples were sputtered with $5 \mathrm{~nm}$ of $\mathrm{Au} / \mathrm{Pd}$ (PECS-682). AFD and the fiber diameter distribution of nanofibrous webs were calculated directly from SEM images by measuring the diameter of about 100 fibers.

The proton nuclear magnetic resonance $\left({ }^{1} \mathrm{H}\right.$ NMR) spectra were recorded at $400 \mathrm{MHz}$ (Bruker DPX-400). $\mathrm{HP} \beta \mathrm{CD} /$ limonene-IC-NF, $\mathrm{M} \beta \mathrm{CD} /$ limonene-IC-NF, and $\mathrm{HP} \gamma \mathrm{CD} /$ limonene-IC-NF $(20 \mathrm{mg} / \mathrm{mL})$ were dissolved in DMSO- $d_{6}$ to evaluate the molar ratio of CDs and limonene in each $\mathrm{CD} /$ limonene-IC by integrating the peak ratio of the characteristic chemical shifts corresponding to $\mathrm{CD}$ and limonene. Integration of the chemical shifts $(\delta)$ given in parts per million (ppm) was performed with Mestrenova software.

Thermogravimetric analysis (TGA, TA Q500, USA) was used to determine the thermal properties of limonene, $\mathrm{HP} \beta \mathrm{CD}-\mathrm{NF}, \mathrm{M} \beta \mathrm{CD}$ $\mathrm{NF}, \mathrm{HP} \gamma \mathrm{CD}-\mathrm{NF}, \mathrm{HP} \beta \mathrm{CD} /$ limonene-IC-NF, $\mathrm{M} \beta \mathrm{CD} /$ limonene-IC$\mathrm{NF}$, and $\mathrm{HP} \gamma \mathrm{CD} /$ limonene-IC-NF. TGA was conducted under a nitrogen atmosphere by heating the samples from 25 to $450{ }^{\circ} \mathrm{C}$ at a heating rate of $20^{\circ} \mathrm{C} / \mathrm{min}$. Differential scanning calorimetry (DSC, TA Q2000, USA) analyses were also performed on $\mathrm{HP} \beta \mathrm{CD}-\mathrm{NF}, \mathrm{M} \beta \mathrm{CD}$ $\mathrm{NF}, \mathrm{HP} \gamma \mathrm{CD}-\mathrm{NF}, \mathrm{HP} \beta \mathrm{CD} /$ limonene-IC-NF, $\mathrm{M} \beta \mathrm{CD} /$ limonene-IC$\mathrm{NF}$, and $\mathrm{HP} \gamma \mathrm{CD} /$ limonene-IC-NF at a heating rate of $20{ }^{\circ} \mathrm{C} / \mathrm{min}$ from 25 to $200{ }^{\circ} \mathrm{C}$ under a flow of nitrogen.

The crystalline structure of $\mathrm{HP} \beta \mathrm{CD}-\mathrm{NF}, \mathrm{M} \beta \mathrm{CD}-\mathrm{NF}, \mathrm{HP} \gamma \mathrm{CD}-\mathrm{NF}$, $\mathrm{HP} \beta \mathrm{CD} /$ limonene-IC-NF, $\mathrm{M} \beta \mathrm{CD} /$ limonene-IC-NF, and $\mathrm{HP} \gamma \mathrm{CD} /$ limonene-IC-NF were investigated in the range of $2 \theta=5-30^{\circ}$ via Xray diffraction (XRD) (PANalytical X'Pert powder diffractometer) using $\mathrm{Cu} \mathrm{K} \alpha$ radiation in a powder diffraction configuration. XRD was not carried out for limonene because it is a liquid compound at RT.

The infrared spectra of limonene, $\mathrm{HP} \beta \mathrm{CD}-\mathrm{NF}, \mathrm{M} \beta \mathrm{CD}-\mathrm{NF}$, $\mathrm{HP} \gamma \mathrm{CD}-\mathrm{NF}, \mathrm{HP} \beta \mathrm{CD} /$ limonene-IC-NF, $\mathrm{M} \beta \mathrm{CD} /$ limonene-IC-NF, and $\mathrm{HP} \gamma \mathrm{CD}$ /limonene-IC-NF were obtained via a Fourier transform infrared spectrometer (FTIR) (Bruker-VERTEX 70). The samples were prepared as pellets by mixing limonene and nanofibers with potassium bromide $(\mathrm{KBr})$ for the measurement. The scans $(64)$ were recorded between 4000 and $400 \mathrm{~cm}^{-1}$ at a resolution of $4 \mathrm{~cm}^{-1}$.

The cumulative amount of limonene released from $\mathrm{HP} \beta \mathrm{CD} /$ limonene-IC-NF, $\mathrm{M} \beta \mathrm{CD} /$ limonene-IC-NF, and $\mathrm{HP} \gamma \mathrm{CD} /$ limoneneIC-NF was measured using headspace gas chromatography-mass spectrometry (HS GC-MS) for $3 \mathrm{~h}$. The instrument was an Agilent Technologies $7890 \mathrm{~A}$ gas chromatograph coupled to an Agilent Technologies 5975C inert MSD combined with a triple-axis detector. The used capillary column was an HP-5MS (Hewlett-Packard, Avondale, PA) $(30 \mathrm{~m} \times 0.25 \mathrm{~mm}$ i.d., $0.25 \mu \mathrm{m}$ film thickness $)$. Ten milligrams of nanofiber samples was taken from the aluminum foil and placed in $20 \mathrm{~mL}$ headspace glass vials. The vials including the nanofiber samples were agitated at $500 \mathrm{rpm}$ at 37,50 , and $75^{\circ} \mathrm{C}$. The syringe temperatures were also 37,50 , and $75^{\circ} \mathrm{C}$. Vapor $(250 \mu \mathrm{L})$ was injected from vials into the HS GC-MS by using a headspace injector. The oven temperature was programmed as follows: initial $40{ }^{\circ} \mathrm{C}$ (held for $3 \mathrm{~min}$ ) and from 40 to $140{ }^{\circ} \mathrm{C}$ at a rate of $10{ }^{\circ} \mathrm{C} / \mathrm{min}$ (held for 3 $\mathrm{min})$. The HS GC-MS was operated in a splitless and selected ion monitoring (SIM) modes. The NIST MS Search 2.0 library was used to decide the limonene peak. The release experiments were performed in triplicate, and the results were reported as average \pm standard deviation.

To evaluate the long-term release of $\mathrm{CD} /$ limonene-IC-NFs, $\mathrm{HP} \beta \mathrm{CD} /$ limonene-IC-NF, $\mathrm{M} \beta \mathrm{CD} /$ limonene-IC-NF, and $\mathrm{HP} \gamma \mathrm{CD} /$ limonene-IC-NF were kept separately at RT and $18 \%$ relative humidity for 100 days in the open air in the laboratory. Then, TGA measurements were made at predetermined time intervals (50th day and 100th day).

The antibacterial activity of limonene, $\mathrm{HP} \beta \mathrm{CD} /$ limonene-IC-NF, $\mathrm{M} \beta \mathrm{CD} /$ limonene-IC-NF, and $\mathrm{HP} \gamma \mathrm{CD} /$ limonene-IC-NF was tested against Escherichia coli (E. coli, ATCC 10536) and Staphylococcus aureus (S. aureus, ATCC 25923) according to a colony-counting method. E. coli and $S$. aureus bacteria were grown in nutrient broth medium ( $3 \mathrm{~g} / \mathrm{L}$ yeast extract, $15 \mathrm{~g} / \mathrm{L}$ peptone, and $6 \mathrm{~g} / \mathrm{L}$ sodium chloride) for $24 \mathrm{~h}$ on a shaker at $100 \mathrm{rpm}$ and $37^{\circ} \mathrm{C}$. UV-sterilized nanofibers $(20 \mathrm{mg})$ and limonene $(1.6 \mathrm{mg})$ were immersed in the culture suspension that contains approximately $10^{8}$ colony-forming units (cfu's) $/ \mathrm{mL}$. In this step, nanofibers easily dissolve in the culture suspension. After $24 \mathrm{~h}$ of incubation and shaking at $37^{\circ} \mathrm{C}$, different dilutions $\left(10^{1}\right.$ to $\left.10^{9}\right)$ were made by successively adding $1 \mathrm{~mL}$ of culture to $9 \mathrm{~mL}$ of phosphate buffer solution. Then, $0.1 \mathrm{~mL}$ of the diluted culture was spread on a nutrient agar plate and incubated at 37 ${ }^{\circ} \mathrm{C}$ for $24 \mathrm{~h}$. The number of colonies was counted four times for each sample.

The antibacterial activity (\%) of limonene and CD/limonene-ICNFs is defined as follows

$$
\text { antibacterial activity }(\%)=\frac{A-B}{A} \times 100
$$

where $A$ and $B$ are the numbers of colonies $(\mathrm{cfu} / \mathrm{mL})$ before and after the nanofibers were added, respectively.

Computational Method. The first-principles calculations based on density functional theory (DFT) $)^{34,35}$ were performed by using the Vienna ab initio simulation package. ${ }^{36,37}$ The exchange correlation was approximated within the generalized gradient approximation ${ }^{38}$ including the van der Waals correction. ${ }^{39}$ The element potentials were described by the projector augmented-wave method (PAW) ${ }^{40}$ using a plane-wave basis set with a kinetic energy cutoff of $520 \mathrm{eV}$. The initial structures of $\mathrm{HP} \beta \mathrm{CD}, \mathrm{M} \beta \mathrm{CD}$, and $\mathrm{HP} \gamma \mathrm{CD}$ were obtained from the Cambridge Structural Database. ${ }^{41}$ To optimize the structure of IC and limonene, the conjugate gradient algorithm without any constraints has been utilized by setting convergence criteria for the total energy and force of $10^{-4} \mathrm{eV}$ and $10^{-2} \mathrm{eV} / \AA$, respectively. The solvent effect on the formation of inclusion complexes has been elucidated by using an implicit solvent model, which includes dispersive interactions. ${ }^{42}$ This model splits the system into an explicit part (solute), which is treated quantum mechanically, and an implicit part (solvent), which is treated as a continuum, all combined within the ab inito method ${ }^{43-45}$ and implemented in VASP (VASPsol). ${ }^{45}$

\section{RESULTS AND DISCUSSION}

Phase Solubility Studies. The phase solubility profiles of $\mathrm{HP} \beta \mathrm{CD} /$ limonene, $\mathrm{M} \beta \mathrm{CD} /$ limonene, and $\mathrm{HP} \gamma \mathrm{CD} /$ limonene systems are presented in Supporting Information Figure S1. The obtained results clearly prove that the solubility of limonene has been increased up to $32 \mathrm{mM} \mathrm{HP} \beta \mathrm{CD}$ in the $\mathrm{HP} \beta \mathrm{CD}$ /limonene system, and beyond this concentration it starts to decrease. This might be due to the formation of a less water-soluble complex at a higher concentration of $\mathrm{HP} \beta C D$. However, the solubility of limonene has been increased linearly for $\mathrm{M} \beta \mathrm{CD} /$ limonene and $\mathrm{HP} \gamma \mathrm{CD} /$ limonene. Therefore, it could be concluded that the solubility curve of $\mathrm{HP} \beta \mathrm{CD} /$ limonene dictates the $A_{n}$ type, whereas $M \beta C D /$ limonene and $\mathrm{HP} \gamma \mathrm{CD} /$ limonene represent $\mathrm{A}_{\mathrm{L}}$-type solubility diagrams. In addition, the linear solubility performance of limonene in $\mathrm{M} \beta \mathrm{CD}$ and $\mathrm{HP} \gamma \mathrm{CD}$ systems reveals the 1:1 complex formation.

Molecular Modeling of CD/Limonene-IC. Although the thermodynamics of complexation reactions primarily involves van der Waals and hydrophobic interactions between guest molecule and $\mathrm{CD}$, this process can also induce the removal of water molecules from the $\mathrm{CD}$ cavity, resulting in the rearrangement of the inclusion complex (IC). Therefore, we carried out a structural optimization of limonene, CDs $(\mathrm{HP} \beta \mathrm{CD}, \mathrm{M} \beta \mathrm{CD}$, and $\mathrm{HP} \gamma \mathrm{CD})$ and their IC in vacuum, followed by optimizations in an aqueous medium. The guest molecule (single limonene) is introduced into the wide rim of 
the cavity of $\mathrm{HP} \beta \mathrm{CD}, \mathrm{M} \beta \mathrm{CD}$, and $\mathrm{HP} \gamma \mathrm{CD}$ at various positions and two different orientations. These orientations include (i) a head, consisting of a methyl group, and (ii) a tail, consisting of an ethyl group of limonene headed inward toward the wide rim of the CD cavity as shown Figure 2a-c.

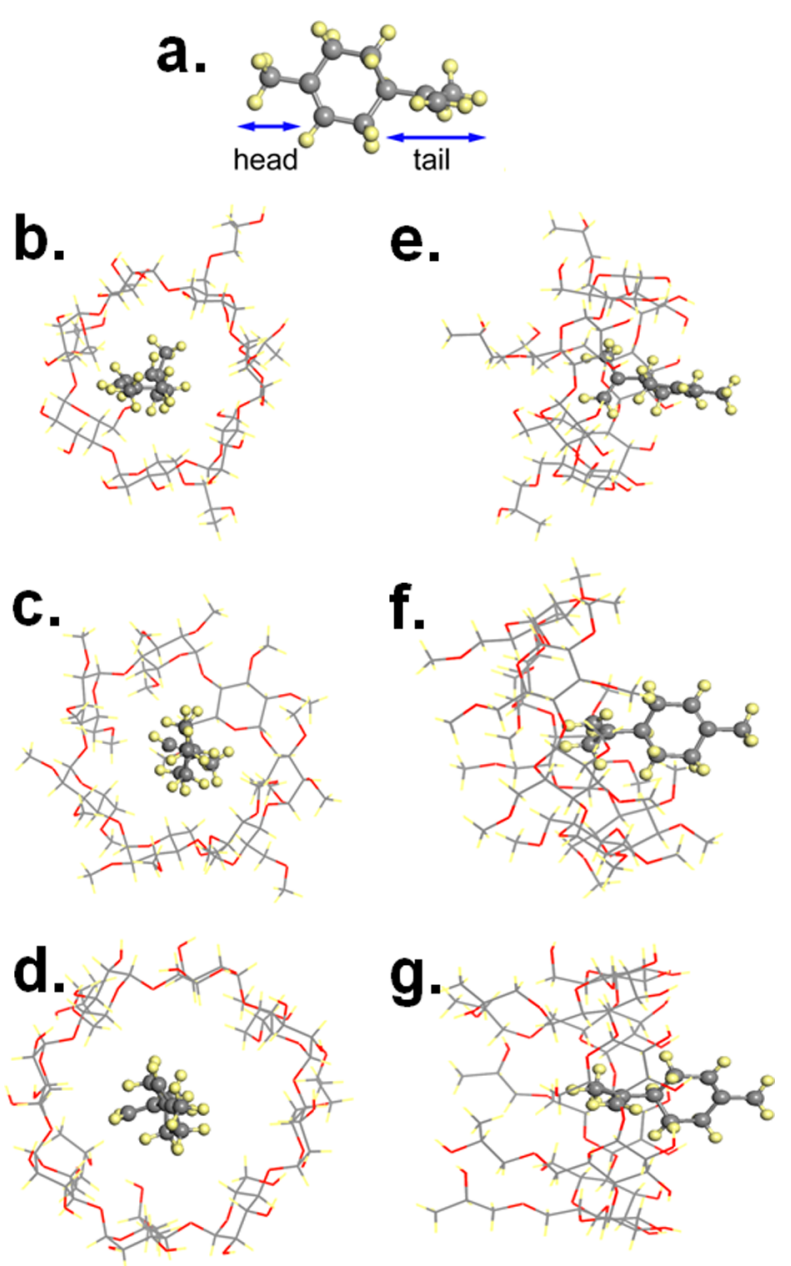

Figure 2. (a) Chemical structure of limonene; top view of ICs of (b) $\mathrm{HP} \beta \mathrm{CD}$, (c) $\mathrm{M} \beta \mathrm{CD}$, and (d) $\mathrm{HP} \gamma \mathrm{CD}$; and side view of ICs of (e) $\mathrm{HP} \beta \mathrm{CD}$, (f) $\mathrm{M} \beta \mathrm{CD}$, and (g) $\mathrm{HP} \gamma \mathrm{CD}$ with limonene in an aqueous medium. Gray, red, and yellow spheres represent carbon, oxygen, and hydrogen atoms, respectively.

The complexation energy $\left(E_{\text {comp }}\right)$ for the lowest-energy configuration of these ICs in 1:1 stoichiometry for three possible orientations is calculated as

$$
E_{\text {comp }}=E_{\mathrm{CD}}+E_{\text {guest }}-E_{\mathrm{IC}}
$$

where $E_{\mathrm{CD}}, E_{\text {guest }}$ and $E_{\mathrm{IC}}$ are the total energy of CD (HP $\beta \mathrm{CD}$, $\mathrm{M} \beta \mathrm{CD}$, and $\mathrm{HP} \gamma \mathrm{CD}$ ), the guest limonene molecule, and IC, respectively. All energies are calculated in an aqueous medium. The results for 1:1 stoichiometry are summarized in Table 1 . Our results indicate that limonene can form IC with all considered types of CDs with varying $E_{\text {comp }}$ depending on the orientation of limonene and the type of $\mathrm{CD}$. Because of the relative size matching between the cavity and the limonene molecule and the polarity of methyl groups, the strongest binding is obtained for $\mathrm{M} \beta \mathrm{CD}$ with the tail orientation of limonene.
Table 1. Complexation and Solvation Energies of Limonene within $\mathrm{HP} \beta \mathrm{CD}, \mathrm{M} \beta \mathrm{CD}$, and $\mathrm{HP} \gamma \mathrm{CD}$

\begin{tabular}{lcccc}
\multicolumn{1}{c}{ host } & guest & $\begin{array}{c}E_{\text {comp }}(\text { head }) \\
\mathrm{kcal} / \mathrm{mol}\end{array}$ & $\begin{array}{c}E_{\text {comp }}(\text { tail }) \\
\mathrm{kcal} / \mathrm{mol}\end{array}$ & $\begin{array}{c}E_{\text {solv }} \\
\mathrm{kcal} / \mathrm{mol}\end{array}$ \\
$\mathrm{HP} \beta \mathrm{CD}$ & limonene & & & -0.66 \\
$\mathrm{M} \beta \mathrm{CD}$ & limonene & 9.7 & 11.7 & -74.2 \\
$\mathrm{HP} \gamma \mathrm{CD}$ & limonene & 10.7 & 12.6 & -29.5 \\
& limone & 5.9 & 7.1 & -89.4 \\
\hline
\end{tabular}

In addition, the solvation energies of bare limonene and ICs are calculated in order to rank their solubility in water. The solvation energy $\left(E_{\text {solv }}\right)$ in an aqueous medium is calculated as

$$
E_{\text {solv }}=E_{(\text {solvated })}-E_{\text {(vacuum) }}
$$

where $E_{\text {(solvated) }}$ and $E_{\text {(vacuum) }}$ are the total energy of molecules in solvent and vacuum, respectively. The calculated $E_{\text {solv }}$ of bare limonene is $-0.66 \mathrm{kcal} / \mathrm{mol}$, which is very low and suggests poor solubility in water. On the other hand, $E_{\text {solv }}$ values of ICs within $\mathrm{HP} \beta \mathrm{CD}, \mathrm{M} \beta \mathrm{CD}$, and $\mathrm{HP} \gamma \mathrm{CD}$ in water are -74.2 , -29.5 , and $-89.4 \mathrm{kcal} / \mathrm{mol}$, respectively, asserting exothermic solvation reactions for all ICs. The IC within $\mathrm{HP} \gamma \mathrm{CD}$ has the highest solubility, and the IC within $\mathrm{M} \beta \mathrm{CD}$ has a lower solubility in water compared to the other ICs.

Morphology Analysis of Nanofibers. The morphological investigation clearly represents bead-free and uniform $\mathrm{HP} \beta \mathrm{CD} /$ limonene-IC-NF, $\mathrm{M} \beta \mathrm{CD} /$ limonene-IC-NF, and $\mathrm{HP} \gamma \mathrm{CD} /$ limonene-IC-NF (Figure $3 a-c)$. The average fiber diameters

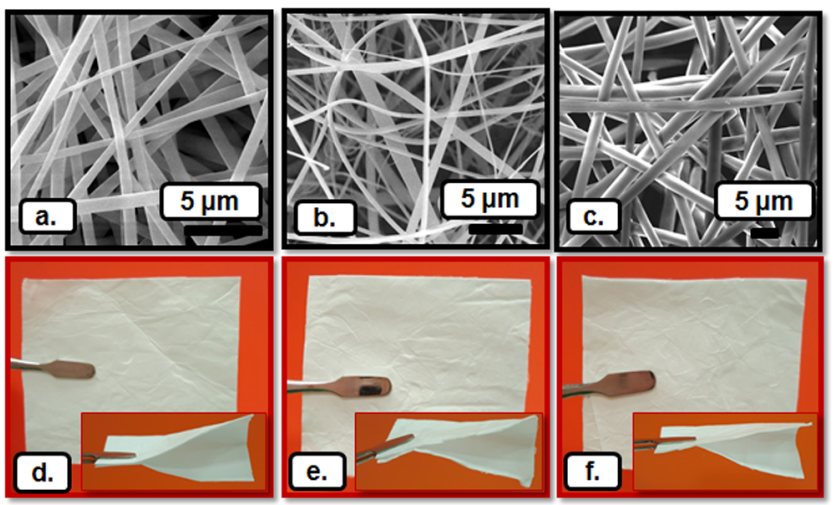

Figure 3. SEM images of electrospun nanofibers obtained from solutions of (a) $\mathrm{HP} \beta \mathrm{CD} /$ limonene-IC, (b) $\mathrm{M} \beta \mathrm{CD} /$ limonene-IC, and (c) $\mathrm{HP} \gamma \mathrm{CD} /$ limonene-IC. Photographs of (d) $\mathrm{HP} \beta \mathrm{CD} /$ limonene-IC$\mathrm{NF}$, (e) $\mathrm{M} \beta \mathrm{CD} /$ limonene-IC-NF, and (f) $\mathrm{HP} \gamma \mathrm{CD} /$ limonene-IC-NF.

(AFDs) of $\mathrm{HP} \beta \mathrm{CD} /$ limonene-IC-NF, $\mathrm{M} \beta \mathrm{CD} /$ limonene-IC$\mathrm{NF}$, and $\mathrm{HP} \gamma \mathrm{CD} /$ limonene-IC-NF were found to be $710 \pm$ $470,405 \pm 210$, and $1450 \pm 500 \mathrm{~nm}$, respectively. The change in the diameter of $\mathrm{CD} /$ limonene-IC nanofibers (CD/limoneneIC-NF) was due to the viscosity and conductivity differences between the solutions (Table 2). The measured conductivity was in the order of $\mathrm{M} \beta \mathrm{CD} /$ limonene-IC solution $>\mathrm{HP} \beta \mathrm{CD} /$ limonene-IC solution $>\mathrm{HP} \gamma \mathrm{CD} /$ limonene-IC solution. Thus, it is proven that the higher conductivity of $\mathrm{M} \beta \mathrm{CD} /$ limonene-IC solution leads to a lower diameter of $\mathrm{M} \beta \mathrm{CD} /$ limonene-IC-NF as compared to that of other nanofibers. Likewise, $\mathrm{HP} \gamma \mathrm{CD} /$ limonene-IC-NF has the highest diameter among all CD/ limonene-IC-NFs because of the higher viscosity and lower conductivity of $\mathrm{HP} \gamma \mathrm{CD} /$ limonene-IC solution compared to those of other solutions. The photographs of free-standing 
Table 2. Properties of the Solutions Used for Electrospinning and Morphological Characteristics of the Resulting Nanofibers

\begin{tabular}{|c|c|c|c|c|c|c|}
\hline solutions & $\% \operatorname{CD}(\mathrm{w} / \mathrm{v})^{a}$ & $\%$ limonene $(\mathrm{w} / \mathrm{w})^{b}$ & viscosity $(\mathrm{Pa} \cdot \mathrm{s})$ & conductivity $(\mu \mathrm{S} / \mathrm{cm})$ & average fiber diameter $(\mathrm{nm})$ & fiber morphology \\
\hline $\mathrm{HP} \beta \mathrm{CD} /$ limonene-IC & 200 & 8.53 & 0.087 & 241 & $710 \pm 470$ & bead free nanofibers \\
\hline $\mathrm{M} \beta \mathrm{CD} /$ limonene-IC & 200 & 10.63 & 0.106 & 999 & $405 \pm 210$ & bead free nanofibers \\
\hline $\mathrm{HP} \gamma \mathrm{CD} /$ limonene-IC & 200 & 7.75 & 0.168 & 2.24 & $1450 \pm 500$ & bead free nanofibers \\
\hline
\end{tabular}

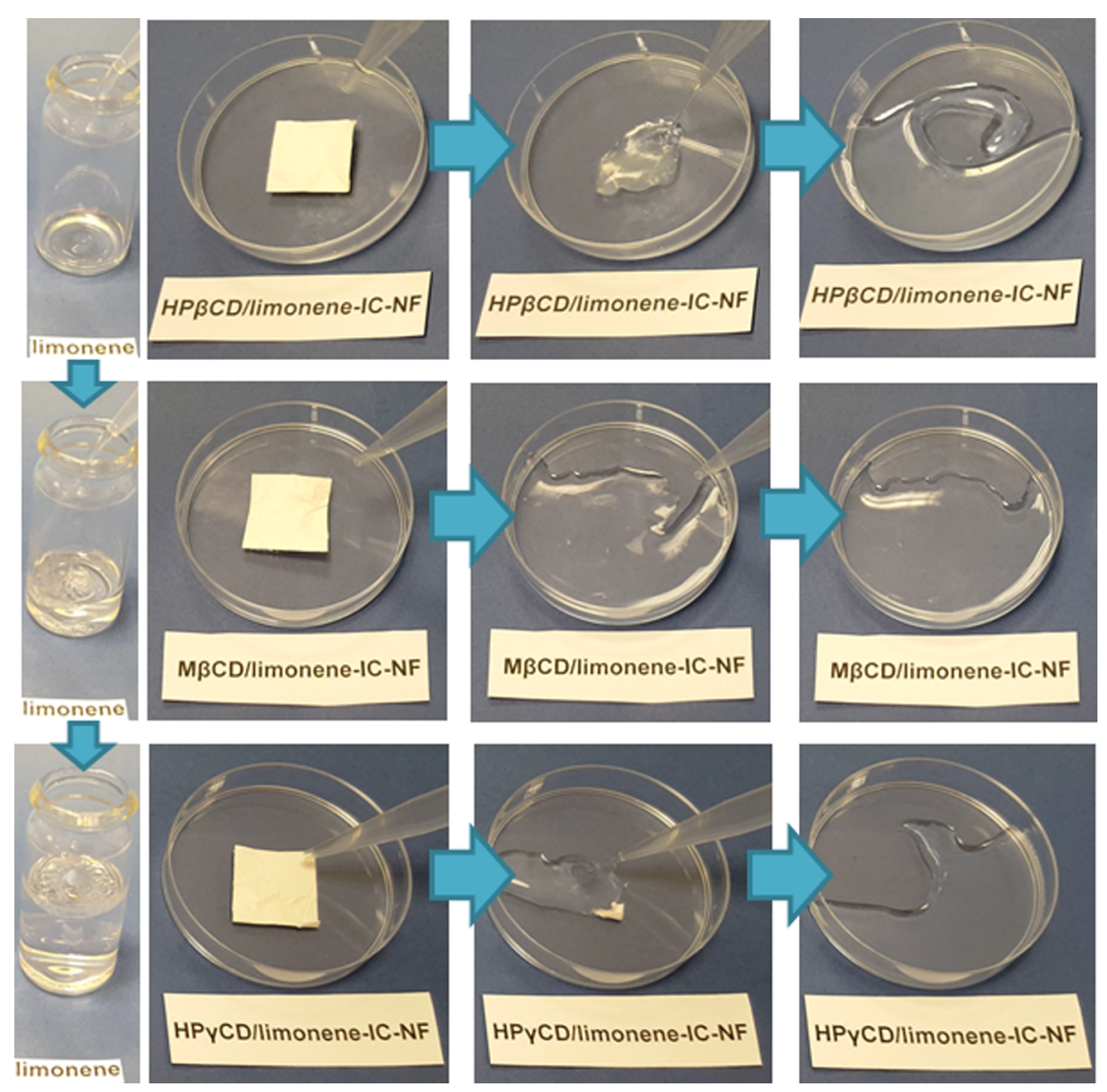

Figure 4. Presentation of the solubility behavior of pure limonene and $\mathrm{HP} \beta \mathrm{CD} /$ limonene-IC-NF, $\mathrm{M} \beta \mathrm{CD} /$ limonene-IC-NF, and $\mathrm{HP} \gamma \mathrm{CD} /$ limoneneIC-NF in water.

$\mathrm{HP} \beta \mathrm{CD} /$ limonene-IC-NF, $\mathrm{M} \beta \mathrm{CD} /$ limonene-IC-NF, and $\mathrm{HP} \gamma \mathrm{CD} /$ limonene-IC-NF webs clearly represent their flexible and easily handled nature, which indicates that all $\mathrm{CD} /$ limonene-IC-NF webs have excellent mechanical integrity even though they are composed of CDs that are amorphous small molecules (Figure $3 \mathrm{~d}-\mathrm{f}$ ). The solubility of limonene, $\mathrm{HP} \beta \mathrm{CD} /$ limonene-IC-NF, $\mathrm{M} \beta \mathrm{CD} /$ limonene-IC-NF, and $\mathrm{HP} \gamma \mathrm{CD} /$ limonene-IC-NF is shown in Figure 4 and Supporting Information videos 1 and 2 . The observed results evidently show that $\mathrm{CD} /$ limonene-IC-NFs completely dissolve in water within seconds; however, limonene does not dissolve, and an oily compound is easily visible on the surface.

Molar Ratio of CD/Limonene-IC. Supporting Information Figure $\mathrm{S} 2 \mathrm{a}-\mathrm{c}$ shows the proton nuclear magnetic resonance $\left({ }^{1} \mathrm{H}\right.$ NMR) spectra of $\mathrm{HP} \beta \mathrm{CD} /$ limonene-IC-NF, $\mathrm{M} \beta \mathrm{CD} /$ limonene-IC-NF, and $\mathrm{HP} \gamma \mathrm{CD} /$ limonene-IC-NF. The molar ratio between $\mathrm{CD}(\mathrm{HP} \beta \mathrm{CD}, \mathrm{M} \beta \mathrm{CD}$, and $\mathrm{HP} \gamma \mathrm{CD})$ and limonene in $\mathrm{CD} /$ limonene-IC-NFs was calculated from the integration of the peak ratio between the peaks of $\mathrm{HP} \beta \mathrm{CD}$, $\mathrm{M} \beta \mathrm{CD}$, and $\mathrm{HP} \gamma \mathrm{CD}(1.029,4.9$, and $1.029 \mathrm{ppm})$ and limonene (1.616 ppm) as 1.00:0.42, 1.00:0.78, and 1.00:0.38 for $\mathrm{HP} \beta \mathrm{CD} /$ limonene-IC-NF, $\mathrm{M} \beta \mathrm{CD} /$ limonene-IC-NF, and
$\mathrm{HP} \gamma \mathrm{CD} /$ limonene-IC-NF, respectively. Therefore, it is concluded that 42,78 , and $38 \%$ of the limonene was preserved in $\mathrm{HP} \beta \mathrm{CD} /$ limonene-IC-NF, $\mathrm{M} \beta \mathrm{CD} /$ limonene-IC-NF, and $\mathrm{HP} \gamma \mathrm{CD} /$ limonene-IC-NF, respectively. Therefore, the calculated amount of limonene in $\mathrm{CD} /$ limonene-IC-NFs suggested that a significant amount of limonene was preserved in $\mathrm{M} \beta \mathrm{CD} /$ limonene-IC-NF. Besides, much more limonene evaporated from $\mathrm{HP} \beta \mathrm{CD} /$ limonene-IC-NF and $\mathrm{HP} \gamma \mathrm{CD} /$ limonene-IC-NF during solution preparation, electrospinning, or storage.

Thermal Analysis of Nanofibers. Thermal gravimetric analysis (TGA) of limonene, $\mathrm{HP} \beta \mathrm{CD}-\mathrm{NF}, \mathrm{M} \beta \mathrm{CD}-\mathrm{NF}$, $\mathrm{HP} \gamma \mathrm{CD}-\mathrm{NF}, \mathrm{HP} \beta \mathrm{CD} /$ limonene-IC-NF, $\mathrm{M} \beta \mathrm{CD} /$ limonene-IC$\mathrm{NF}$, and $\mathrm{HP} \gamma \mathrm{CD} /$ limonene-IC-NF is given in Figure $5 \mathrm{a}-\mathrm{c}$. Thermal evaporation of pure limonene started at about $50{ }^{\circ} \mathrm{C}$ and continued until $150^{\circ} \mathrm{C}$. Pristine $\mathrm{HP} \beta \mathrm{CD}-\mathrm{NF}, \mathrm{M} \beta \mathrm{CD}-\mathrm{NF}$, and $\mathrm{HP} \gamma \mathrm{CD}-\mathrm{NF}$ exhibited two weight losses below $100{ }^{\circ} \mathrm{C}$ and above $275{ }^{\circ} \mathrm{C}$ that belong to the water loss and main thermal degradation of each $\mathrm{CD}$, respectively. ${ }^{21}$ Three stages of weight loss were observed for $\mathrm{HP} \beta \mathrm{CD} /$ limonene-IC-NF. The first weight loss below $100{ }^{\circ} \mathrm{C}$ belongs to the water loss, and second and third weight losses between 100 and $230{ }^{\circ} \mathrm{C}$ and above 275

${ }^{\circ} \mathrm{C}$ correspond to limonene and $\mathrm{HP} \beta \mathrm{CD}$, respectively. The 


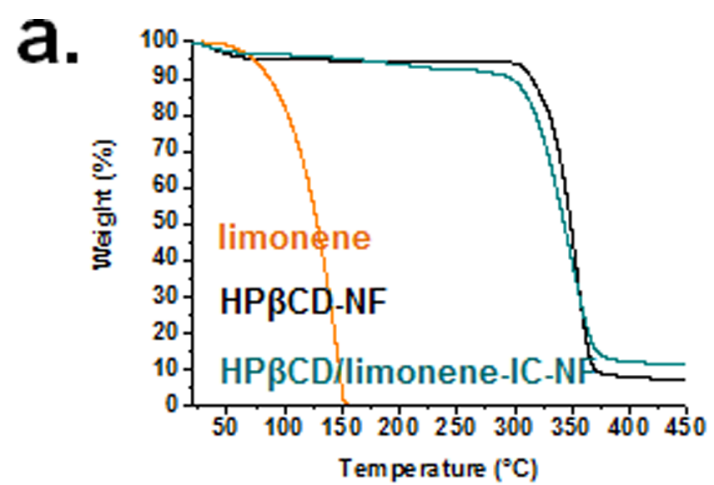

b.

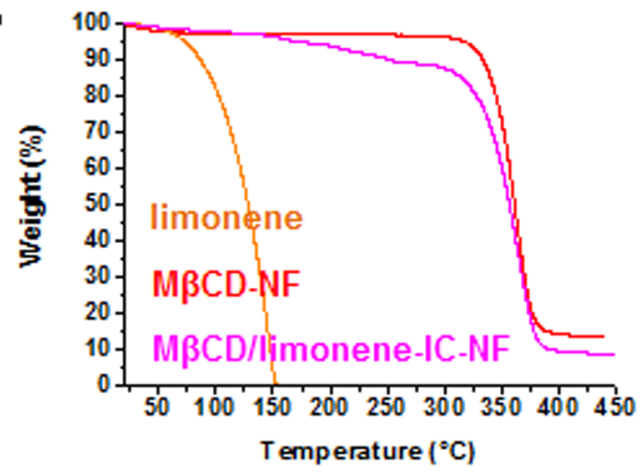

C.

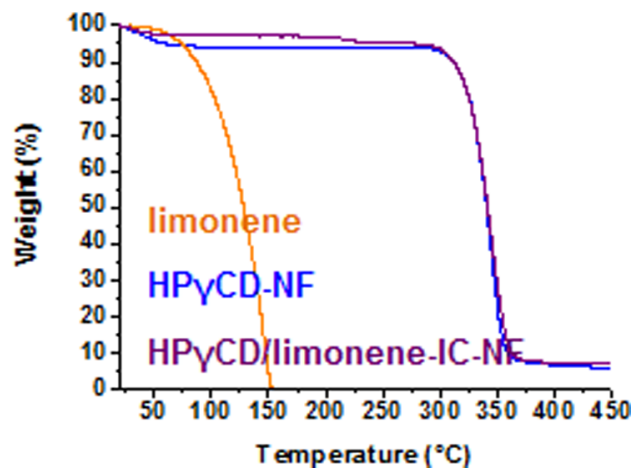

Figure 5. TGA thermograms of (a) limonene, $\mathrm{HP} \beta \mathrm{CD}-\mathrm{NF}$, and $\mathrm{HP} \beta \mathrm{CD} /$ limonene-IC-NF; (b) limonene, $\mathrm{M} \beta \mathrm{CD}-\mathrm{NF}$, and $\mathrm{M} \beta \mathrm{CD} /$ limonene-IC-NF; and (c) limonene, $\mathrm{HP} \gamma \mathrm{CD}-\mathrm{NF}$, and $\mathrm{HP} \gamma \mathrm{CD} /$ limonene-IC-NF.

shifting of the onset of the thermal evaporation of limonene to higher temperature suggested IC formation between $\mathrm{HP} \beta \mathrm{CD}$ and limonene. Four steps of weight loss existed in the case of $\mathrm{M} \beta \mathrm{CD} /$ limonene-IC-NF. The initial weight loss below $100{ }^{\circ} \mathrm{C}$ was due to water loss, the second and third weight losses ranging between 120 and $170{ }^{\circ} \mathrm{C}$ and 170 and $270{ }^{\circ} \mathrm{C}$ were attributed to limonene. The shifting of the evaporation onset of limonene up to 120 and $170{ }^{\circ} \mathrm{C}$ confirms IC formation between $\mathrm{M} \beta \mathrm{CD}$ and limonene. Moreover, the presence of two steps for limonene that are at a temperature higher than for free limonene showed that there might be two types of complex formation between $\mathrm{M} \beta \mathrm{CD}$ and limonene. However, the second complex in the third step shows a stronger interaction with limonene compared to that for the first complex formed in the second step. The last weight loss observed in $\mathrm{M} \beta \mathrm{CD} /$ limonene-IC-NF is above $300{ }^{\circ} \mathrm{C}$ and belongs to the degradation of $\mathrm{M} \beta \mathrm{CD}$. $\mathrm{HP} \gamma \mathrm{CD} /$ limonene-IC-NF exhibited three steps of weight loss: the initial weight loss below $100{ }^{\circ} \mathrm{C}$ belongs to the water, the second weight loss between 165 and $245^{\circ} \mathrm{C}$ is due to the limonene, and the third weight loss above $300{ }^{\circ} \mathrm{C}$ corresponds to the thermal degradation of HP $\gamma \mathrm{CD}$. A shift was observed in the thermal evaporation onset of limonene to higher temperature, and this shift was due to the inclusion complexation between $\mathrm{HP} \gamma \mathrm{CD}$ and limonene. Furthermore, the thermal stability of the second complex in $\mathrm{M} \beta \mathrm{CD} /$ limonene-IC-NF was higher than for the complexes formed in $\mathrm{HP} \beta \mathrm{CD} /$ limonene-IC-NF and $\mathrm{HP} \gamma \mathrm{CD} /$ limoneneIC-NF. This result indicated the existence of strong and more stable complexation between $\mathrm{M} \beta \mathrm{CD}$ and limonene, which was also confirmed with the computational modeling studies. Here, the methyl groups of $\mathrm{M} \beta \mathrm{CD}$ might increase the hydrophobic interaction and provide higher stability to the system. ${ }^{46}$

From the TGA data, the amounts of limonene in $\mathrm{HP} \beta \mathrm{CD} /$ limonene-IC-NF, $\mathrm{M} \beta \mathrm{CD} /$ limonene-IC-NF, and $\mathrm{HP} \gamma \mathrm{CD} /$ limonene-IC-NF were calculated to be $\sim 3.66 \%, \sim 8.45 \%$, $(2.71 \%$ and $5.74 \%$ belong to the first and second complex, respectively), and $\sim 2.05 \%$ (w/w, with respect to $\mathrm{CD}$ ), and these calculations confirmed that $43 \%, 80 \%$ (26\% and 54\%), and $26 \%$ of the limonene remained during the preparation, electrospinning processes, and storage, respectively. According to TGA results, the molar ratios of $\mathrm{HP} \beta \mathrm{CD}, \mathrm{M} \beta \mathrm{CD}$, and $\mathrm{HP} \gamma \mathrm{CD}$ to limonene were calculated to be 1.00:0.43, 1.00:0.80, and 1.00:0.27, respectively. The molar ratio of $\mathrm{CD} /$ limonene in $\mathrm{CD} /$ limonene-IC-NF samples calculated from the TGA data agreed well with the data obtained from ${ }^{1} \mathrm{H}$ NMR. Therefore, limonene was preserved to a great extent in $\mathrm{M} \beta \mathrm{CD} /$ limoneneIC-NF; however, a certain amount of limonene present in $\mathrm{HP} \beta \mathrm{CD}$ /limonene-IC-NF and $\mathrm{HP} \gamma \mathrm{CD} /$ limonene-IC-NF was lost during the preparation, electrospinning, or storage. Nevertheless, it is anticipated that the CD-IC nanofiber matrix could preserve a much higher limonene content than could the polymeric nanofiber matrix. For instance, in our previous studies, we have seen that volatile molecules such as vanillin, ${ }^{14}$ allyl isothiocyanate, ${ }^{10}$ and geraniol ${ }^{13}$ could not be preserved at all in electrospun poly(vinyl alcohol) (PVA) nanofibers without CD-IC.

Differential scanning calorimetry (DSC) curves of $\mathrm{HP} \beta \mathrm{CD}$ NF, $\mathrm{M} \beta \mathrm{CD}-\mathrm{NF}, \mathrm{HP} \gamma \mathrm{CD}-\mathrm{NF}, \mathrm{HP} \beta \mathrm{CD} /$ limonene-IC-NF, $\mathrm{M} \beta \mathrm{CD} /$ limonene-IC-NF, and $\mathrm{HP} \gamma \mathrm{CD} /$ limonene-IC-NF are given in Figure 6a. The dehydration of CDs in HP $\beta$ CD-NF, $\mathrm{M} \beta \mathrm{CD}-\mathrm{NF}$, and $\mathrm{HP} \gamma \mathrm{CD}-\mathrm{NF}$ is observed as typical broad endothermic peaks between 25 and 160, 25-155, and 25-155 ${ }^{\circ} \mathrm{C}$, respectively. The endothermic peaks in the DSC curves of $\mathrm{CD} /$ limonene-IC-NFs were in the ranges of 65-160, 70-140, and $50-170{ }^{\circ} \mathrm{C}$ for $\mathrm{HP} \beta \mathrm{CD} /$ limonene-IC-NF, $\mathrm{M} \beta \mathrm{CD} /$ limonene-IC-NF, and $\mathrm{HP} \gamma \mathrm{CD} /$ limonene-IC-NF, respectively. The enthalpies of endothermic transitions in $\mathrm{HP} \beta \mathrm{CD}-\mathrm{NF}$, $\mathrm{M} \beta \mathrm{CD}-\mathrm{NF}$, and $\mathrm{HP} \gamma \mathrm{CD}-\mathrm{NF}$ were 329,99 , and $255 \mathrm{~J} / \mathrm{g}$, whereas the enthalpies of $\mathrm{HP} \beta \mathrm{CD} /$ limonene-IC-NF, $\mathrm{M} \beta \mathrm{CD} /$ limonene-IC-NF, and $\mathrm{HP} \gamma \mathrm{CD} /$ limonene-IC-NF were 131, 54, and $229 \mathrm{~J} / \mathrm{g}$, respectively. The reduction in the enthalpy of $\mathrm{HP} \beta \mathrm{CD}-\mathrm{NF}, \mathrm{M} \beta \mathrm{CD}-\mathrm{NF}$, and HP $\gamma \mathrm{CD}-\mathrm{NF}$ after the complexation of limonene confirmed the complexation by displacing a certain number of water molecules in the cavity of CDs with limonene. $^{47}$

Structural Characterization of Nanofibers. Figure $6 \mathrm{~b}$ shows the X-ray diffraction (XRD) patterns of $\mathrm{HP} \beta \mathrm{CD}-\mathrm{NF}$, $\mathrm{M} \beta \mathrm{CD}-\mathrm{NF}, \mathrm{HP} \gamma \mathrm{CD}-\mathrm{NF}, \mathrm{HP} \beta \mathrm{CD} /$ limonene-IC-NF, $\mathrm{M} \beta \mathrm{CD} /$ limonene-IC-NF, and $\mathrm{HP} \gamma \mathrm{CD} /$ limonene-IC-NF. $\mathrm{HP} \beta \mathrm{CD}$, $\mathrm{M} \beta \mathrm{CD}$, and $\mathrm{HP} \gamma \mathrm{CD}$ are known to be amorphous molecules. 

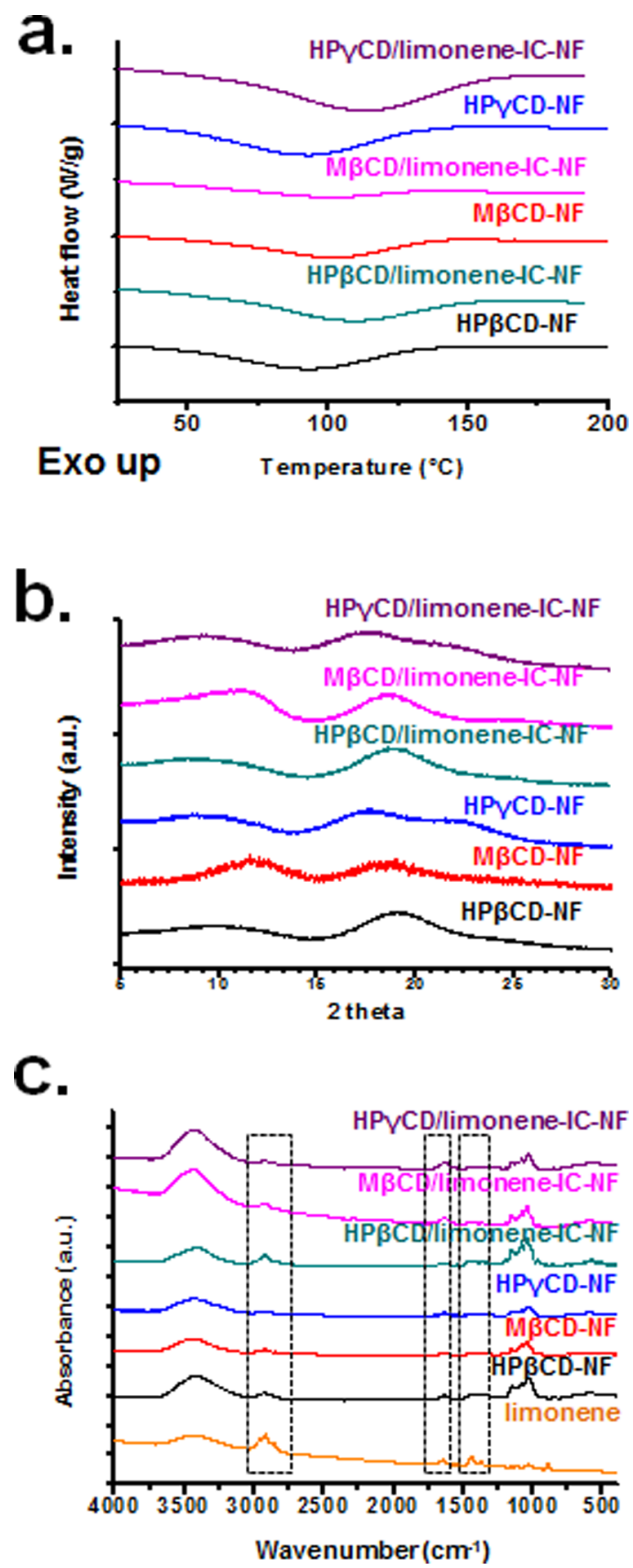

Figure 6. (a) DSC thermograms of $\mathrm{HP} \beta \mathrm{CD}-\mathrm{NF}, \mathrm{HP} \beta \mathrm{CD} /$ limoneneIC-NF, $\mathrm{M} \beta \mathrm{CD}-\mathrm{NF}, \mathrm{M} \beta \mathrm{CD} /$ limonene-IC-NF, $\mathrm{HP} \gamma \mathrm{CD}-\mathrm{NF}$, and $\mathrm{HP} \gamma \mathrm{CD} /$ limonene-IC-NF. (b) XRD patterns of $\mathrm{HP} \beta \mathrm{CD}-\mathrm{NF}$, $\mathrm{M} \beta \mathrm{CD}-\mathrm{NF}, \mathrm{HP} \gamma \mathrm{CD}-\mathrm{NF}, \mathrm{HP} \beta \mathrm{CD} /$ limonene-IC-NF, $\mathrm{M} \beta \mathrm{CD} /$ limonene-IC-NF, and $\mathrm{HP} \gamma \mathrm{CD} /$ limonene-IC-NF. (c) FTIR spectra of limonene, $\mathrm{HP} \beta \mathrm{CD}-\mathrm{NF}, \mathrm{M} \beta \mathrm{CD}-\mathrm{NF}, \mathrm{HP} \gamma \mathrm{CD}-\mathrm{NF}, \mathrm{HP} \beta \mathrm{CD} /$ limoneneIC-NF, $\mathrm{M} \beta \mathrm{CD} /$ limonene-IC-NF, and $\mathrm{HP} \gamma \mathrm{CD} /$ limonene-IC-NF.

The observed amorphous peak in $\mathrm{HP} \beta \mathrm{CD}-\mathrm{NF}, \mathrm{M} \beta \mathrm{CD}-\mathrm{NF}$, and $\mathrm{HP} \gamma \mathrm{CD}-\mathrm{NF}$ further confirms the native amorphous nature of $\mathrm{HP} \beta \mathrm{CD}, \mathrm{M} \beta \mathrm{CD}$, and $\mathrm{HP} \gamma \mathrm{CD}$ molecules. Similarly, an amorphous pattern was also observed for $\mathrm{HP} \beta \mathrm{CD} /$ limoneneIC-NF, $\mathrm{M} \beta \mathrm{CD} /$ limonene-IC-NF, and $\mathrm{HP} \gamma \mathrm{CD} /$ limonene-ICNF. More importantly, the absence of a limonene peak in $\mathrm{HP} \beta \mathrm{CD} /$ limonene-IC-NF, $\mathrm{M} \beta \mathrm{CD} /$ limonene-IC-NF, and $\mathrm{HP} \gamma \mathrm{CD} /$ limonene-IC-NF confirmed the formation of the complex.
The chemical structures of limonene, $\mathrm{HP} \beta \mathrm{CD}-\mathrm{NF}, \mathrm{M} \beta \mathrm{CD}$ $\mathrm{NF}, \mathrm{HP} \gamma \mathrm{CD}-\mathrm{NF}, \mathrm{HP} \beta \mathrm{CD} /$ limonene-IC-NF, $\mathrm{M} \beta \mathrm{CD} /$ limonene-IC-NF, and $\mathrm{HP} \gamma \mathrm{CD} /$ limonene-IC-NF were investigated by FTIR spectroscopy (Figure 6c). The characteristic absorption peaks of CDs observed at around 1030, 1080, $1157,1638,2925$, and $3401 \mathrm{~cm}^{-1}$ are due to the coupled C-C and $\mathrm{C}-\mathrm{O}$ stretching vibrations, antisymmetric stretching vibration of the $\mathrm{C}-\mathrm{O}-\mathrm{C}$ glycosidic bridge, $\mathrm{H}-\mathrm{OH}$ bending, $\mathrm{C}-\mathrm{H}$ stretching, and $\mathrm{O}-\mathrm{H}$ stretching, respectively. The characteristic peaks of limonene are seen at $888 \mathrm{~cm}^{-1}(\mathrm{C}=$ C), $1379 \mathrm{~cm}^{-1}\left(\mathrm{CH}_{3}\right.$ symmetric bending), $1446 \mathrm{~cm}^{-1}\left(\mathrm{CH}_{2}\right.$ bending), $1650 \mathrm{~cm}^{-1}$ ( $\mathrm{C}=\mathrm{C}$ stretching of the exocyclic double bond), and 2850 and $2965 \mathrm{~cm}^{-1}$ (symmetric and antisymmetric stretching of $\mathrm{sp}^{2}$ and $\mathrm{sp}^{3} \mathrm{CH}$ groups). Although the characteristic peaks of limonene and CDs overlap in some regions $\left(1650,2850\right.$, and $\left.2965 \mathrm{~cm}^{-1}\right)$, the intensity increased with the addition of limonene. In addition, the characteristic peaks of limonene at 1378 and $1446 \mathrm{~cm}^{-1}$ are observed in $\mathrm{HP} \beta \mathrm{CD} /$ limonene-IC-NF and $\mathrm{M} \beta \mathrm{CD} /$ limonene-IC-NF. These results showed the presence of limonene in $\mathrm{CD} /$ limonene-IC-NFs.

Release Study. The release results of the limonene from $\mathrm{CD} /$ limonene-IC-NFs as a function of temperature over $3 \mathrm{~h}$ are shown in Figure $7 a-c$. The release of limonene from CD/
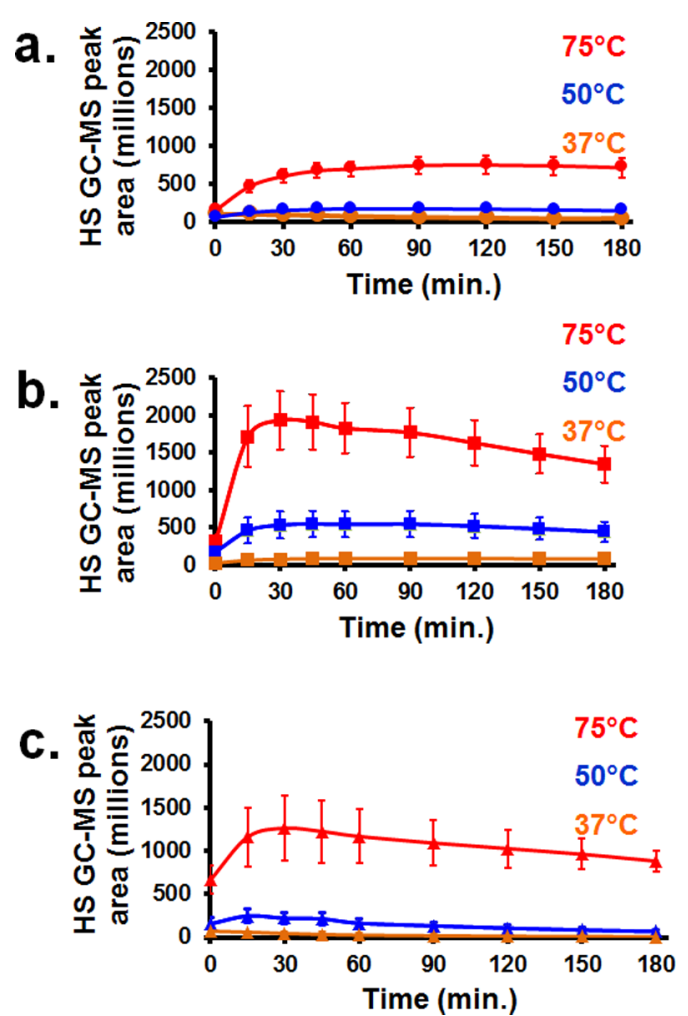

Figure 7. Cumulative release of limonene from (a) $\mathrm{HP} \beta \mathrm{CD} /$ limonene-IC-NF, (b) $\mathrm{M} \beta \mathrm{CD} /$ limonene-IC-NF, and (c) $\mathrm{HP} \gamma \mathrm{CD} /$ limonene-IC-NF at 37,50 , and $75{ }^{\circ} \mathrm{C}(n=3)$. The error bars in the figure represent the standard deviation.

limonene-IC-NFs was increased with increasing temperature from 37 to $75{ }^{\circ} \mathrm{C}$. The variations in the temperature induce the increase in the diffusion coefficient of the molecules. ${ }^{48}$ The total amount of released limonene was in the order of $\mathrm{M} \beta \mathrm{CD} /$ limonene-IC-NF > HP $\gamma \mathrm{CD} /$ limonene-IC-NF > $\mathrm{HP} \beta \mathrm{CD} /$ limonene-IC-NF. On the other hand, the rate of release was 
highest from $\mathrm{HP} \gamma \mathrm{CD} /$ limonene-IC-NF and lowest from $\mathrm{M} \beta \mathrm{CD} /$ limonene-IC-NF at 37,50 , and $75^{\circ} \mathrm{C}$.

The better preservation of limonene shown in ${ }^{1} \mathrm{H}$ NMR and TGA data might be the reason for the large amount of limonene released from $\mathrm{M} \beta \mathrm{CD} /$ limonene-IC-NF. The higher stability of the complex formed in $\mathrm{M} \beta \mathrm{CD} /$ limonene-IC-NF as shown in the TGA results could be responsible for the slower release of limonene from the nanofibers. Moreover, the superior size fit between modified $\beta \mathrm{CDs}$ compared to that of $\mathrm{HP} \gamma \mathrm{CD}$ might be another reason for the quick release of $\mathrm{HP} \gamma \mathrm{CD} /$ limonene-IC-NF. As discussed above, the computational modeling studies are well correlated with the experimental results where the complexation energy was calculated in the order of $\mathrm{M} \beta \mathrm{CD} /$ limonene-IC $>\mathrm{HP} \beta \mathrm{CD} /$ limonene-IC > HP $\gamma \mathrm{CD} /$ limonene-IC.

TGA measurements were also performed to investigate the long-term release of $\mathrm{HP} \beta \mathrm{CD} /$ limonene-IC-NF, $\mathrm{M} \beta \mathrm{CD} /$ limonene-IC-NF, and $\mathrm{HP} \gamma \mathrm{CD} /$ limonene-IC-NF, and the results are summarized in Figure 8 . Most of the limonene

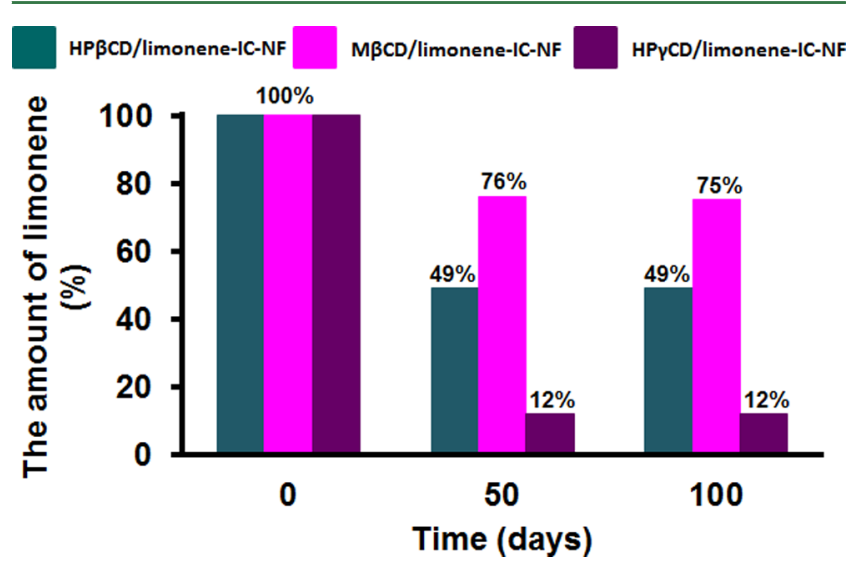

Figure 8. Amount of limonene in $\mathrm{HP} \beta \mathrm{CD}$ /limonene-IC-NF, $\mathrm{M} \beta \mathrm{CD} /$ limonene-IC-NF, and $\mathrm{HP} \gamma \mathrm{CD} /$ limonene-IC-NF at RT for 100 days.

present in $\mathrm{M} \beta \mathrm{CD} /$ limonene-IC-NF was not released (remaining $75 \%(w / w))$ at the end of 100 days because of the high stability of $\mathrm{M} \beta \mathrm{CD} /$ limonene-IC-NF as discussed previously. Limonene $(51 \% \mathrm{w} / \mathrm{w})$ was released from $\mathrm{HP} \beta \mathrm{CD} /$ limoneneIC-NF at the end of 100 days. The comparatively lower stability of the complex in $\mathrm{HP} \beta \mathrm{CD} /$ limonene-IC-NF could be the reason for the greater amount of limonene released compared to that of $\mathrm{M} \beta \mathrm{CD} /$ limonene-IC-NF. The amount of released limonene was $88 \%(\mathrm{w} / \mathrm{w})$ for $\mathrm{HP} \gamma \mathrm{CD} /$ limonene-IC-NF at the end of 100 days. These results might be due to the excellent size fit between $\mathrm{HP} \beta \mathrm{CD}$ and $\mathrm{M} \beta \mathrm{CD}$ with limonene and correlate well with the short-term release experiments in which $\mathrm{HP} \gamma \mathrm{CD} /$ limonene-IC-NF released limonene quickly compared to $\mathrm{HP} \beta \mathrm{CD} /$ limonene-IC-NF and $\mathrm{M} \beta \mathrm{CD} /$ limonene-IC-NF. In previous studies conducted by our group, most of the vanillin, allyl isothiocyanate, and geraniol that was loaded was lost during electrospinning and storage without CD-IC in electrospun PVA nanofibers. ${ }^{14,10,13}$ Here, we observed that a considerable amount of limonene remained in the nanofibrous matrix of $\mathrm{HP} \beta \mathrm{CD} /$ limonene-IC-NF and $\mathrm{M} \beta \mathrm{CD} /$ limonene-ICNF even after a long storage time (100 days) on the shelf.

Antibacterial Activity. Essential oils are known to have antibacterial activity resulting from the terpene constituents disrupting the bacterial membrane in both Gram-negative and Gram-positive bacteria. ${ }^{49}$ Figure 9 presents the effect of

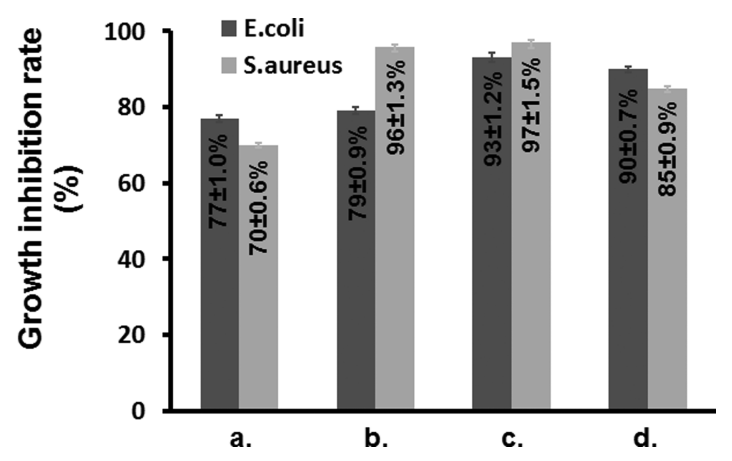

Figure 9. Growth inhibition rate (\%) of E. coli and S. aureus in (a) limonene, (b) $\mathrm{HP} \beta \mathrm{CD} /$ limonene-IC-NF, (c) $\mathrm{M} \beta \mathrm{CD} /$ limonene-IC$\mathrm{NF}$, and (d) $\mathrm{HP} \gamma \mathrm{CD} /$ limonene-IC-NF $(n=3)$. The error bars in the figure represent the standard deviation.

limonene and CD/limonene-IC-NFs on the growth inhibition rate of Escherichia coli (E. coli) and Staphylococcus aureus (S. aureus). $\mathrm{CD} /$ limonene-IC-NFs possessed strong antibacterial activity against $E$. coli and $S$. aureus that was even greater than that of limonene. The higher antibacterial activity of $\mathrm{CD} /$ limonene-IC-NFs could be due to the higher solubility and preservation rate of limonene in $\mathrm{CD} /$ limonene-IC-NFs. Namely, limonene, $\mathrm{HP} \beta \mathrm{CD} /$ limonene-IC-NF, $\mathrm{M} \beta \mathrm{CD} /$ limonene-IC-NF, and $\mathrm{HP} \gamma \mathrm{CD} /$ limonene-IC-NF exhibited $77 \pm 1.0$, $79 \pm 0.9,93 \pm 1.2$, and $90 \pm 0.7 \%$ against $E$. coli and $70 \pm 0.6$, $96 \pm 1.3,97 \pm 1.5$, and $85 \pm 0.9 \%$ against $S$. aureus, respectively. $\mathrm{M} \beta \mathrm{CD} /$ limonene-IC-NF had the strongest antibacterial effect for $E$. coli and $S$. aureus, which could be due to the better preservation of limonene shown in ${ }^{1} \mathrm{H} N M R$, TGA, and HS GC-MS. Furthermore, it is known that Grampositive bacteria have a thin layer of peptidoglycan, whereas Gram-negative bacteria have a thick lipid bilayer on the outside. Therefore, Gram-positive bacteria are much more susceptible to antibacterial agents than are Gram-negative bacteria. ${ }^{50}$ These results clarified the higher antibacterial activity of $\mathrm{CD} /$ limonene-IC-NFs against $S$. aureus compared to that of E. coli that is expected to inhibit the growth of bacteria in the mouth causing bad breath as an oral care strip.

Here, by using electrospinning we present the production of free-standing nanofibrous webs from three modified CDs $(\mathrm{HP} \beta \mathrm{CD}, \mathrm{M} \beta \mathrm{CD}$, and $\mathrm{HP} \gamma \mathrm{CD}$ ) and volatile essential oil, limonene, without using a polymer matrix. The solubility of limonene was increased with all $\mathrm{CD}$ types as seen in phase solubility diagrams. The stoichiometry of the complexes was 1:1 from the computational and experimental studies. SEM images revealed that all $\mathrm{CD} /$ limonene-IC-NFs had bead-free morphology. TGA, DSC, and XRD confirmed the formation of the complexes. $\mathrm{HP} \beta \mathrm{CD} /$ limonene-IC-NF, $\mathrm{M} \beta \mathrm{CD} /$ limoneneIC-NF, and $\mathrm{HP} \gamma \mathrm{CD} /$ limonene-IC-NF preserved up to 43,80 , and $38 \%$ of limonene according to the ${ }^{1} \mathrm{H}$ NMR and TGA results, respectively. The short-term $(3 \mathrm{~h})$ release of limonene evaluated at three different temperatures $\left(37,50\right.$, and $\left.75{ }^{\circ} \mathrm{C}\right)$ via $\mathrm{HS} \mathrm{GC}-\mathrm{MS}$ revealed that $\mathrm{M} \beta \mathrm{CD} /$ limonene-IC-NF released much more limonene as a result of the better preservation compared to that of $\mathrm{HP} \beta \mathrm{CD} /$ limonene-IC-NF and $\mathrm{HP} \gamma \mathrm{CD}$ /limonene-IC-NF. Long-term open air (100 days at $\mathrm{RT}$ ) release tests of limonene from $\mathrm{CD} /$ limonene-IC-NFs were performed as well. Much less limonene was released from $\mathrm{M} \beta \mathrm{CD} /$ limonene-IC-NF when compared to $\mathrm{HP} \beta \mathrm{CD} /$ limonene-IC-NF and $\mathrm{HP} \gamma \mathrm{CD} /$ limonene-IC-NF in long-term open air release tests. These results confirm the highest stability of 
the complexes in $\mathrm{M} \beta \mathrm{CD} /$ limonene-IC-NF among the three $\mathrm{CD} /$ limonene-IC-NFs web sample. In addition, the rate of release in short- and long-term release studies was also slow in the case of $\mathrm{M} \beta \mathrm{CD} /$ limonene-IC-NF, which is likely due to the higher stability of limonene in $\mathrm{M} \beta \mathrm{CD} /$ limonene-IC-NF than in $\mathrm{HP} \beta \mathrm{CD} /$ limonene-IC-NF and $\mathrm{HP} \gamma \mathrm{CD} /$ limonene-IC-NF as mentioned in the TGA results. Antibacterial activity test results indicated that $\mathrm{CD} /$ limonene-IC-NFs presented high antibacterial activity against both Gram-negative (E. coli) and Grampositive (S. aureus) bacteria. Finally, it was observed that $\mathrm{CD} /$ limonene-IC-NFs were dissolved in water in a few seconds. In conclusion, the results suggested the potential of $\mathrm{CD} /$ limonene-IC nanofibrous webs to be used in food or healthcare areas such as an oral care strip for improving oral hygiene while freshening the breath, owing to the large amount of preserved limonene with enhanced solubility and high antibacterial activity.

\section{ASSOCIATED CONTENT}

\section{S Supporting Information}

, and videos showing the solubility of limonene and $\mathrm{CD} /$ limonene-IC-NFs presented and available as free of charge via the Internet at The Supporting Information is available free of charge on the ACS Publications website at DOI: 10.1021/ acs.jafc.6b02632.

Phase solubility diagrams and ${ }^{1} \mathrm{H}$ NMR results (PDF)

Videos showing the solubility of limonene (MPG)

Videos showing the solubility of CD/limonene-IC-NFs (MPG)

\section{AUTHOR INFORMATION}

\section{Corresponding Author}

*Tel: +90-3122908987. E-mail: tamer@unam.bilkent.edu.tr.

\section{Notes}

The authors declare no competing financial interest.

\section{ACKNOWLEDGMENTS}

We express our special thanks to Dr. Asli Celebioglu for the electrospinning of cyclodextrin nanofibers. Z.A., Z.I.Y., and F.K.S. are grateful for TUBITAK-BIDEB, and Z.A. and Z. I.Y. are also grateful for TUBITAK (project no. 213M185) for Ph.D. scholarships. T.U. acknowledges The Scientific and Technological Research Council of Turkey (TUBITAK)Turkey (project no. 213M185) for funding this research. T.U. and E.D. acknowledge support from The Turkish Academy of Sciences - Outstanding Young Scientists Award Program (TUBA-GEBIP), Turkey. The calculations were performed at TUBITAK ULAKBIM, High Performance and Grid Computing Center (TR-Grid e-Infrastructure).

\section{REFERENCES}

(1) Del Valle, E. M. M. Cyclodextrins and their uses: a review. Process Biochem. 2004, 39 (9), 1033-1046.

(2) Szejtli, J. Introduction and general overview of cyclodextrin chemistry. Chem. Rev. 1998, 98 (97), 1743-1753.

(3) Wendorff, J. H.; Agarwal, S.; Greiner, A. Electrospinning: Materials, Processing and Applications; John Wiley \& Sons: Weinheim, Germany, 2012.

(4) McKee, M. G.; Wilkes, G. L.; Colby, R. H.; Long, T. E. Correlations of solution rheology with electrospun fiber formation of linear and branched polyesters. Macromolecules 2004, 37 (5), 17601767.
(5) Celebioglu, A.; Uyar, T. Cyclodextrin nanofibers by electrospinning. Chem. Commun. 2010, 46 (37), 6903-5.

(6) Celebioglu, A.; Uyar, T. Electrospinning of nanofibers from nonpolymeric systems: polymer-free nanofibers from cyclodextrin derivatives. Nanoscale 2012, 4, 621-631.

(7) Celebioglu, A.; Uyar, T. Electrospinning of nanofibers from nonpolymeric systems: Electrospun nanofibers from native cyclodextrins. J. Colloid Interface Sci. 2013, 404, 1-7.

(8) Celebioglu, A.; Uyar, T. Electrospun gamma-cyclodextrin $(\gamma$-CD) nanofibers for the entrapment of volatile organic compounds. RSC Adv. 2013, 3, 22891-22895.

(9) Celebioglu, A.; Uyar, T. Green and one-step synthesis of gold nanoparticles incorporated into electrospun cyclodextrin nanofibers. RSC Adv. 2013, 3, 10197-10201.

(10) Aytac, Z.; Dogan, S. Y.; Tekinay, T.; Uyar, T. Release and antibacterial activity of allyl isothiocyanate/ $\beta$-cyclodextrin complex encapsulated in electrospun nanofibers. Colloids Surf., B 2014, 120, $125-131$.

(11) Kayaci, F.; Ertas, Y.; Uyar, T. Enhanced thermal stability of eugenol by cyclodextrin inclusion complex encapsulated in electrospun polymeric nanofibers. J. Agric. Food Chem. 2013, 61 (34), 8156-8165.

(12) Kayaci, F.; Umu, O. C. O.; Tekinay, T.; Uyar, T. Antibacterial electrospun poly (lactic acid) (PLA) nanofibrous webs incorporating triclosan/cyclodextrin inclusion complexes. J. Agric. Food Chem. 2013, 61, 3901-3908.

(13) Kayaci, F.; Sen, H. S.; Durgun, E.; Uyar, T. Functional electrospun polymeric nanofibers incorporating geraniol-cyclodextrin inclusion complexes: High thermal stability and enhanced durability of geraniol. Food Res. Int. 2014, 62, 424-431.

(14) Kayaci, F.; Uyar, T. Encapsulation of vanillin/cyclodextrin inclusion complex in electrospun polyvinyl alcohol (PVA) nanowebs: Prolonged shelf-life and high temperature stability of vanillin. Food Chem. 2012, 133, 641-649.

(15) Uyar, T.; Nur, Y.; Hacaloglu, J.; Besenbacher, F. Electrospinning of functional poly (methyl methacrylate) nanofibers containing cyclodextrin-menthol inclusion complexes. Nanotechnology 2009, 20 (12), 125703.

(16) Uyar, T.; Hacaloglu, J.; Besenbacher, F. Electrospun polystyrene fibers containing high temperature stable volatile fragrance/flavor facilitated by cyclodextrin inclusion complexes. React. Funct. Polym. 2009, 69 (3), 145-150.

(17) Uyar, T.; Nur, Y.; Hacaloglu, J.; Besenbacher, F. Electrospun polyethylene oxide (PEO) nanofibers containing cyclodextrin inclusion complex. J. Nanosci. Nanotechnol. 2011, 11, 3949-3958.

(18) Aytac, Z.; Sen, H. S.; Durgun, E.; Uyar, T. Sulfisoxazole/ cyclodextrin inclusion complex incorporated in electrospun hydroxypropyl cellulose nanofibers as drug delivery system. Colloids Surf., B 2015, 128, 331-338.

(19) Canbolat, M. F.; Celebioglu, A.; Uyar, T. Drug delivery system based on cyclodextrin-naproxen inclusion complex incorporated in electrospun polycaprolactone nanofibers. Colloids Surf., B 2014, 115, $15-21$.

(20) Aytac, Z.; Kusku, S. I.; Durgun, E.; Uyar, T. Quercetin $/ \beta$ cyclodextrin inclusion complex embedded nanofibres: Slow release and high solubility. Food Chem. 2016, 197, 864-871.

(21) Celebioglu, A.; Uyar, T. Electrospinning of polymer-free nanofibers from cyclodextrin inclusion complexes. Langmuir 2011, 27 (10), 6218-26.

(22) Celebioglu, A.; Umu, O. C. O.; Tekinay, T.; Uyar, T. Antibacterial electrospun nanofibers from triclosan/cyclodextrin inclusion complexes. Colloids Surf., B 2014, 116, 612-619.

(23) Bakkali, F.; Averbeck, S.; Averbeck, D.; Idaomar, M. Biological effects of essential oils-a review. Food Chem. Toxicol. 2008, 46 (2), 446-475.

(24) Sun, J. D-Limonene: safety and clinical applications. Alternative Med. Rev. 2007, 12 (3), 259-264.

(25) Partanen, R.; Ahro, M.; Hakala, M.; Kallio, H.; Forssell, P. Microencapsulation of caraway extract in $\beta$-cyclodextrin and modified starches. Eur. Food Res. Technol. 2002, 214 (3), 242-247. 
(26) Shiga, H.; Yoshii, H.; Nishiyama, T.; Furuta, T. Flavor encapsulation and release characteristics of spray-dried powder by the blended encapsulant of cyclodextrin and gum arabic. Drying Technol. 2001, 19 (7), 1385-1395.

(27) Kfoury, M.; Auezova, L.; Fourmentin, S.; Greige-Gerges, H. Investigation of monoterpenes complexation with hydroxypropyl- $\beta$ cyclodextrin. J. Inclusion Phenom. Macrocyclic Chem. 2014, 80, 51-60. (28) Ciobanu, A.; Landy, D.; Fourmentin, S. Complexation efficiency of cyclodextrins for volatile flavor compounds. Food Res. Int. 2013, 53 (1), 110-114.

(29) Yoshii, H.; Neoh, T. L.; Beak, S. H.; Furuta, T. Release behavior of flavor encapsulated $\mathrm{CD}$ in slurry solution under boiling conditions. J. Inclusion Phenom. Mol. Recognit. Chem. 2006, 56, 113-116.

(30) Camerlo, A.; Vebert-Nardin, C.; Rossi, R. M.; Popa, A. M. Fragrance encapsulation in polymeric matrices by emulsion electrospinning. Eur. Polym. J. 2013, 49 (12), 3806-3813.

(31) Camerlo, A.; Bühlmann-Popa, A. M.; Vebert-Nardin, C.; Rossi, R. M.; Fortunato, G. Environmentally controlled emulsion electrospinning for the encapsulation of temperature-sensitive compounds. J. Mater. Sci. 2014, 49, 8154-8162.

(32) Fuenmayor, C. A.; Mascheroni, E.; Cosio, M. S.; Piergiovanni, L.; Benedetti, S.; Ortenzi, M.; Schiraldi, A.; Mannino, S. Encapsulation of R-(+)-limonene in edible electrospun nanofibers. Chemical Engineering Transactions. 2013, 1-4 (32), 1771-1776.

(33) Higuchi, T.; Connors, A. K. Phase-solubility techniques. Advances in Analytical Chemistry and Instrumentation. 1965, 4, 117212.

(34) Kohn, W.; Sham, L. J. Self-consistent equations including exchange and correlation effects. Phys. Rev. 1965, 140, A1133-A1138.

(35) Hohenberg, P.; Kohn, W. Inhomogeneous electron gas. Phys. Rev. 1964, 136, B864-B871.

(36) Kresse, G.; Furthmüller, J. Efficient iterative schemes for ab initio total-energy calculations using a plane-wave basis set. Phys. Rev. B: Condens. Matter Mater. Phys. 1996, 54 (16), 11169-11186.

(37) Kresse, G.; Furthmüller, J. Efficiency of ab-initio total energy calculations for metals and semiconductors using a plane-wave basis set. Comput. Mater. Sci. 1996, 6 (1), 15-50.

(38) Perdew, J. P.; Chevary, J. A.; Vosko, S. H.; Jackson, K. A.; Pederson, M. R.; Singh, D. J.; Fiolhais, C. Atoms, molecules, solids, and surfaces: Applications of the generalized gradient approximation for exchange and correlation. Phys. Rev. B: Condens. Matter Mater. Phys. 1992, 46, 6671-6687.

(39) Grimme, S. Semiempirical GGA-type density functional constructed with a long-range dispersion correction. J. Comput. Chem. 2006, 27 (15), 1787-1799.

(40) Blöchl, P. E. Projector augmented-wave method. Phys. Rev. B: Condens. Matter Mater. Phys. 1994, 50 (24), 17953-17979.

(41) Allen, F. H. The Cambridge Structural Database: A quarter of a million crystal structures and rising. Acta Crystallogr., Sect. B: Struct. Sci. 2002, 58 (3), 380-388.

(42) Fattebert, J. L.; Gygi, F. First-principles molecular dynamics simulations in a continuum solvent. Int. J. Quantum Chem. 2003, 93 (2), 139-147.

(43) Andreussi, O.; Dabo, I.; Marzari, N. Revised self-consistent continuum solvation in electronic-structure calculations. J. Chem. Phys. 2012, 136, 064102.

(44) Petrosyan, S. A.; Rigos, A. A.; Arias, T. A. Joint densityfunctional theory: $\mathrm{Ab}$ initio study of $\mathrm{Cr} 2 \mathrm{O} 3$ surface chemistry in solution. J. Phys. Chem. B 2005, 109, 15436.

(45) Mathew, K.; Sundararaman, R.; Letchworth-Weaver, K.; Arias, T. A.; Hennig, R. G. Implicit solvation model for density-functional study of nanocrystal surfaces and reaction pathways. J. Chem. Phys. 2014, 140 (8), 084106.

(46) Mura, P.; Bettinetti, G. P.; Manderioli, A.; Faucci, M. T.; Bramanti, G.; Sorrenti, M. Interactions of ketoprofen and ibuprofen with $\beta$-cyclodextrins in solution and in the solid state. Int. J. Pharm. 1998, 166, 189-203.

(47) Kadam, V. B.; Bamane, G. S.; Raut, G. S. Solubility Enhancement of Nebivolol Hydrochloride using $\beta$-CD Complexation
Technique. International Journal of Current Pharmaceutical Science. 2014, 1 (1), 6-12.

(48) Hu, C. Y.; Chen, M.; Wang, Z. W. Release of thymol, cinnamaldehyde and vanillin from soy protein isolate films into olive oil. Packag. Technol. Sci. 2012, 25, 97-106.

(49) Delaquis, P. J.; Stanich, K.; Girard, B.; Mazza, G. Antimicrobial activity of individual and mixed fractions of dill, cilantro, coriander and eucalyptus essential oils. Int. J. Food Microbiol. 2002, 74, 101-109.

(50) Madigan, M. T.; Martinko, J. M.; Stahl, D.; Clark, D. P. Brock Biology of Microorganisms, 13th ed.; Pearson Education, Inc.: San Francisco, 2012. 